\title{
CAPÍTULOVI
}

\section{Atos retóricos e identidade feminina: a mulher que era "aquilo"}

\section{Introdução}

Qualquer mulher, se encarnada, é mulher de verdade? A resposta óbvia seria um gritante sim, pois o fato de estar no mundo revela a existência verdadeira de um ser que tem vida e presença física comprováveis. Na canção popular, porém, o "de verdade" pode não se contrapor ao "de mentira", mas, sim, ser sinônimo de perfeita ou a construção subjetiva de alguém que, envolto pela paixão, vivencia uma confusão entre o sensível e o inteligível, entre o individual e o social. Pode encerrar uma saudade, enfeitada pela memória, de uma mulher que simbolizava Eros, de modo platoniano, como uma força grande e poderosa com imensa capacidade mediadora e unitiva.

Em outro plano, que mulher, na contemporaneidade, gostaria de ser considerada como objeto? Muitas brasileiras, porém, em meio a uma noitada de carnaval já entoaram, com todas as letras, $A i$, meu Deus, que saudade da Amélia, aquilo sim é que era mulber! Coisificada e enaltecida simultaneamente, a famosa Amélia deixou, no coração de um poeta dolorido, uma saudade muito determinada de um extremado conformismo existencial: às vezes, passava fome ao meu lado. Pior: e achava bonito não ter o que comer. Nos escaninhos da memória do orador, Amélia é a mulher perfeita e, por isso, "de verdade". Afinal, o que é um nome se não o resgate histórico, um aglomerado de enunciações que se amalgamam para dar um significado único e simultaneamente universal a um ser? Hoje, transformada em antonomásia, conhecemos muitas Amélias que têm outros nomes, mas conservam uma aura histórica, marcada na temporalidade pela submissão e subserviência.

1 Este capítulo foi originalmente publicado: FIGUEIREDO, Maria Flávia; MAGALHÃES, Ana Lúcia; FERREIRA, Luiz Antonio. Atos retóricos e identidade feminina: a mulher que era “aquilo". In: FERREIRA, Luiz Antonio; FIGUEIREDO, Maria Flávia; MAGALHÃES, Ana Lúcia (orgs.). As mulheres que a gente canta. Franca, SP: Cristal/Grupo Era, 2016, v. 2, p. 37-56. 
Tudo faz sentido: Amélia é variante de Amália, forma do germânico amalberga, de amal (trabalho) mais berga, (amparo, proteção). É a trabalhadora, a laboriosa, que acolhe, abriga, conforta e protege sem nada pedir em troca. A mulher cantada e a canção singela fixaram-se, pelo encantamento da poesia transformada em discurso, no coração terno dos foliões brasileiros. Criada em 1941, por Ataulfo Alves e Mário Lago, tornou-se emblemática pela tradução de um momento histórico da constituição do feminino no Brasil.

\author{
Saudade da Amélia ${ }^{2}$ \\ Nunca vi fazer tanta exigência \\ Nem fazer o que você me faz. \\ Você não sabe o que é consciência \\ Nem vê que eu sou um pobre rapaz? \\ Você só pensa em luxo e riqueza \\ Tudo o que você vê você quer \\ Ai, meu Deus, que saudade da Amélia! \\ Aquilo sim é que era mulher! \\ Às vezes passava fome ao meu lado \\ $\mathrm{E}$ achava bonito não ter o que comer \\ E quando me via contrariado \\ Dizia: Meu filho, que se há de fazer? \\ Amélia não tinha a menor vaidade. \\ Amélia que era mulher de verdade! \\ (Ataulfo Alves e Mário Lago)
}

A canção tem raízes na realidade: Amélia dos Santos Ferreira, a empregada doméstica que inspirou o clássico samba composto por Ataulfo Alves e Mário Lago, morreu, com 91 anos de idade, em 27 de julho de 2001, no Rio de Janeiro, em razão de uma pneumonia. Desconhecida do grande público enquanto mulher da vida real, a personagem popularizada no samba como "de verdade" foi grande sucesso no Carnaval de 1942. Transformada em uma espécie de hino carnavalesco, presente na memória popular e entoada por todo o Brasil, foi profundamente atacada por inúmeras feministas na década de 60, pois Amélia simboliza, na MPB, o que significa etimologicamente: subserviente, passiva, terna e conformada.

2 ALVES, Ataulfo; LAGO, Mário. Saudade da Amélia. Copyright 1941 by Irmãos Vitale S/A Indústria e Comércio. Todos os direitos autorais reservados para todos os países. All rights reserved. 
A canção toda é construída por meio de um raciocínio apodítico e se sustenta num gênero retórico muito evidente: o laudatório. Enquanto enaltece as qualidades de Amélia, o orador diminui, pela descrição dos atos da nova amada, os sentidos da paixão que vivencia no ato de dizer. Se o $e$ hos $^{3}$ de Amélia conduz o auditório universal ao conforto, a mulher "emancipada" e sem juízo com quem o orador dialoga na canção traz desassossego, sofrimento e intranquilidade.

Evidencia-se, assim, a retórica da manutenção: a lembrança nostálgica e, ao mesmo tempo, suave, de uma pessoa consubstanciada em carinho distante no tempo e agora extinto. Submissa ou predadora, a mulher é o elemento propulsor do desenvolvimento temático do samba de Mário Lago e Ataulfo Alves e amalgama memória e realidade, num conglomerado emotivo próximo das ideias de um Sartre existencialista, ao constatar que o amor é conflito, nunca pode ser plenamente realizável porque qualquer relação entre seres humanos implica uma série de contradições inextrincáveis em que se inclui a limitação da liberdade alheia (SCHOEPFLIN, 2004). Se há amor nessa canção (e sobre isso discutiremos ao longo deste texto), é visto como conflito incurável.

Saudade da Amélia é mesmo um grito de censura e de exaltação de um passado rememorado por um eu que vê o que nunca viu e põe em relevo uma discórdia de concepções sobre o que é útil, justo, belo, honrável e necessário. Há nítida assimetria de posições entre o orador e o auditório particular e, na constituição discursiva, as posições assumidas por um e outro desvelam o poder de troca, de confrontos existenciais que, por sua vez, enfatizam a força das paixões empreendidas no ato retórico.

Pelo discurso da música popular, pois, é possível desvendar na temporalidade histórica, a corporificação de um universo livre - porque artístico - e passional porque humano-, recheado de experiências afetivas em diversas e interessantes dimensões: condição feminina, atitudes passionais, discursos de negociação das distâncias e versos singelos que, num conglomerado de natureza cultural, propagam a retórica das paixões. Nesse sentido, os versos de Saudade da Amélia tornam-se arautos da revelação histórica de subjetividades que se atravessam num incessante movimento patêmico de retomadas discursivas e intertextuais, de tentativas de racionalização do existir e de acordos e desacordos estabelecidos pela força intrínseca da palavra. A potência da retórica, por sua vez, assoalha a historicidade e os movimentos ideológicos que caracterizam um processo de construção do humano no fluir do tempo.

3 Optamos pela grafia e acentuação dos termos gregos utilizados dentro da Língua Portuguesa. Mantivemos o itálico e eliminamos todos os diacríticos de acentuação, uma vez que a acentuação do grego não obedece aos mesmos critérios da Língua Portuguesa; excetuamos os nomes próprios. (Nota das revisoras) 


\section{A Mulher que Virou Aquilo}

O texto foi criado em 1941, bem antes do poderoso movimento encetado pelas feministas no mundo todo. O Brasil, governado por Getúlio Vargas, em pleno Estado Novo, conhecera, no ano anterior, o "salário mínimo", apregoado como o salvador dos pobres, mas o custo de vida se elevava e, menos de três anos depois, o salário já não dava para o mínimo necessário. Os pobres, portanto, continuaram pobres, vivendo sob um regime ditatorial. A queixa do orador, pois, tem razões históricas: Não vê que eu sou um pobre rapaz?

O poema se constrói por meio de uma figura de comunhão: a apóstrofe, uma espécie de interpelação, um pedido de atenção do auditório para que se afaste, de algum modo, da cena enunciativa e deixe aflorar uma voz outra, vinda do passado, de alguém que não tinha a menor vaidade. A evocação pretende culminar numa expressiva antonomásia: a mulher de verdade, para designar Amélia. Com essa figura retórica, caracteristicamente de escolha, o orador cumpre seu propósito de sobrelevar os atributos, qualidades e hábitos de uma mulher para diminuir as ações, consideradas frívolas, de outra. Com esse artifício, situa, pela evocação comparativa, a situação em que se encontra a relação amorosa.

O objetivo, então, é intensificar o enunciado pelo ato de interpelar uma suposta companheira apenas para exprimir censuras, lamentos e expressar uma emoção viva, profunda, dolorida, extremamente passional. $O$ desejo mais evidente do orador é trazer para o contexto retórico um ser que não era o interlocutor: Amélia, vista como parceira distante, em contraponto a uma companheira quase inimiga, alguém que não sabe o que é consciência. Agressivamente narcisístico, o poema de Mário Lago e Ataulfo Alves faz da interrogatividade o maior pilar argumentativo: Não vê que eu sou um pobre rapaz? A partir dessa pergunta cruciante, o orador procura conduzir o seu auditório para uma determinada perspectiva do assunto, para um ângulo interpretativo favorável a seu próprio ponto de vista, com o intento maior de obter adesão.

Já nos primeiros versos, essa interrogação pueril expõe o problema retórico e configura o ethos do orador. O pobre rapaz conota "coitado, necessitado de cuidados". Por outro lado, como se reporta a uma mulher considerada exigente, a posição do adjetivo revela também a condição social do amante: rapaz com poucas posses, que já passara até fome. Como conviver com alguém que tudo o que vê quer e que só pensa em luxo e riqueza? No entender do orador, a solução está em condicionar o fazer da nova amada ao saudoso modelo anterior. A construção desse ethos de carente em todos os sentidos é fundamental para que, no plano argumentativo, os aspectos persuasivos ganhem corpo mais robusto e coerente no restante da canção. 
A construção do ethos da interlocutora, por sua vez, é marcada por uma sequência aditiva e palavras totalizadoras de sentido negativo e quantitativo: Nunca vi fazer tanta exigência, nem fazer o que você me faz; não sabe, nem vê e pela presença marcante de um verbo repetido e repetido: fazer, fazer e faz. Para intensificar e realçar o fazer, o não fazer, não saber e não ver da interlocutora o orador se vale, também, de uma figura de presença muito comum: a repetição do pronome (nem fazer o que você me faz, você não sabe, você só pensa, você não vê, tudo o que você vê você quer), seis vezes repetido em seis versos curtos. A ação que traz o sofrer está enfaticamente situada pela repetição de um mesmo verbo: nem fazer o que você me faz. O dilema está igualmente revelado: embora queira tudo o que vê, a interlocutora não consegue querer o próprio orador, pois a condição inferiorizada não é vista, percebida, levada em conta pela mulher que, traduzida tantas vezes em você, sequer tem um nome identificável na canção. Em termos de constituição do ethos feminino, essa rival de Amélia é apenas uma mulher predadora, sem muita consciência das reais condições do estar no mundo e, portanto, sem muito juízo. É alguém que faz, mas não sabe o que faz e não vế: apenas quer.

Desse modo, para dar uma imagem positiva de si mesmo, o orador vale-se da constituição do ethos de seu auditório particular, a perdulária, por um recurso argumentativo que consiste em denegrir a imagem do outro pela negação do que seria considerado bom e digno: a inominada não revela prudência (phronesis), não demonstra virtudes (arete) e não é benevolente (eunoia). O verso Você não sabe o que é consciência, pois, acentua a ausência de virtudes esperadas e não presentes na constituição da personalidade demonstrada dessa não-Amélia: não tem perspicácia para entender as necessidades do companheiro, não revela discernimento, discrição, equilíbrio, bom senso, tento, prudência ou ponderação no controle da vaidade e da ambição. Por isso, é considerada como alguém sem razão ou sensatez.

Quando, porém, essas três qualidades (phronesis, areté e eunoia) são conjugadas positivamente, o ethos remanescente é digno de credibilidade, respeito e admiração, como acontece, no poema, com a imagem criada para retratar, na concepção do orador, aquela que é considerada mulher de verdade. O ethos de Amélia se revela também pelo fazer, mas, numa antítese gritante, antes de agir, a mulher sem vaidade pergunta como proceder: Meu filho, o que se há de fazer? Atenta, também via, mas esse ver era um exercício de observação das eventuais contrariedades do companheiro. Amélia, diferentemente da "desajuizada", não colocava o querer como prioritário, sabia que o amado era um pobre rapaz e, por isso, num rasgo extremado de encantamento, até achava bonito não ter o que comer. Amélia não encantava pelo querer, mas pelo prazer de conviver e estar no mundo, sem se importar prioritariamente com o ter. 
Embora sintéticos, os versos projetam imagens tão vivas e enérgicas dessa mulher em suas atitudes e disposições que caracterizam uma hipotipose, a figura retórica que intensifica, pela descrição, uma cena ou circunstância com cores tão intensas que o auditório, descentrado emocionalmente, tem a sensação de que as percebe pessoalmente. Os versos curtos dos oradores estão na memória discursiva do povo brasileiro. Talvez o verbo mais impressionante seja passava, pois resume um modo de ser: passar é atravessar, é ultrapassar, transpor algo, exceder um limite. As atitudes de Amélia transcendiam o querer e o ultrapassar um obstáculo centrava-se na alteridade, nos desejos e aspirações do outro, na capacidade de perceber o invisível e transformá-lo positivamente para preservar, pelo respeito, o que há de imanente no ser com quem se convive. Para a construção do ethos daquela que não sabe o que é consciência, o orador enumera defeitos, pauta-se no lugar retórico da quantidade. Para reconstruir os motivos da saudade e evidenciar virtudes, vale-se do lugar da qualidade e concentra aí toda uma concepção de feminino, acumulada ao longo dos séculos: aquilo sim é que era mulher.

O orador, premido por circunstâncias desfavoráveis que colocam o conviver entre necessidades, alteridades e carências afetivas, acentua os aspectos persuasivos do discurso. A melancolia é o sentimento que se evidencia, justamente pela incompreensão demonstrada pela amada de submeter-se à reprodução secular e clichezada dos papéis masculinos e femininos. E são justamente os clichês que promovem a infelicidade do orador: a saudade, um sentimento por si dolorido, infiltra-se na fala e, desolado diante da situação, o homem denota seu estado de espírito frustrado e algo indignado. Revela, então, sua fragilidade e seu sofrimento por não ter diante de si o espelho, o modelo de mulher que idealizara. A não-Amélia, sem consciência, fica, pois, capturada numa trama cultural simbólica que a impede de ser ela mesma. Por esse caminho argumentativo, instaura-se a rivalidade, uma relação polêmica organizada em torno do objeto amado. $O$ fazer da mulher se traduz na descrição de provas contundentes justamente para fragilizá-la diante de uma rival já esmaecida no tempo, mas muito presente e potencializada na fala do amante. O diálogo posto em ação é produto do discurso autoritário, uma vez que pretende acentuar as características ligadas a uma hierarquia de valores peremptoriamente determinada nos extremos do certo e do errado.

O orador, assim, compõe um cenário passional, hiperbólico, para concentrar o sofrer e a indignação já nos primeiros momentos de interlocução. Consideremos, primeiramente, a existência de um espaço público e de atores que nele interagem. Esse espaço, por sua vez, se constrói na percepção que têm os diferentes grupos e atores que nele interatuam. Há múltiplas vozes, portanto, concebendo e configurando um ambiente discursivo. Não se ouve a resposta da mulher inominada, mas a tensividade retórica demonstra a existência de um movimento de disputa, de configuração e de reconfiguração intermitente sobre o 
estar no mundo. $\mathrm{O}$ discurso, por sua função intrínseca, desvela, progressivamente, a arena de conflitos e de disputa de valores e de reivindicações sociais. $\mathrm{O}$ orador esforça-se por gerir as diferenças e clama pelo estabelecimento coerente do que entende por identidade cultural.

A fala do orador encerra em si um conglomerado de discursos outros, herdados no fio da História. Num plano amplo, o homem constrói sua identidade na relação dinâmica com a alteridade e, de um modo ou de outro, assimila o movimento das crenças e paixões que movem seu grupo cultural. O texto, lugar da interação, dramatiza essa relação. Nesse processo, a tematização da condição feminina, por exemplo, suscita uma reflexão que, inevitavelmente, envolve sentidos advindos de outros discursos (animados por alguma intenção), situados em contextos históricos, sociais e afetivos em que o auditório se insere ou conheceu por herança. $\mathrm{O}$ resultado são efeitos de sentido. Tais efeitos se introjetam no seio social e o moldam de um modo ou outro em consonância com o efeito persuasivo provocado. $\mathrm{O}$ orador assimilou um modo de conceber o feminino que era característico em seu tempo e, por certo, deixava repercutir em sua memória histórica outras canções centradas no paradigma da doméstica, como Emília ${ }^{4}$, um anagrama de Amélia, de Wilson Barbosa e Haroldo Lobo, gravada em 1941, ano da composição da música de Alves e Lago:

Eu quero uma mulher

Que saiba lavar e cozinhar, que, de manhã cedo, me acorde na hora de trabalhar.

Só existe uma

e sem ela eu não vivo em paz.

Emília, Emília, Emília, eu não posso mais.

Ninguém sabe igual a ela

preparar o meu café.

Não desfazendo das outras,

Emília é mulher.

Papai do céu é quem sabe

a falta que ela me faz

Emília, Emília, Emília,

Eu não posso mais.

$4 \quad$ BARBOSA, Wilson; LOBO, Haroldo. Emília. Gravada em 1941. Disponível em: < https://www.letras. mus.br/wilson-batista/265221/>. Acesso em 14 de maio de 2014. 
Etimologicamente, Emília é a versão feminina de Emílio. O nome, supostamente originado a partir do latim Aemilius, derivado de aemulus, que quer dizer "rival". Outro étimo possível liga-se à mitologia grega: Aimylios, o filho de Numa, significa "o que fala de modo agradável". Por extensão, assim como Amélia, Emília é aquela que tem uma linguagem "graciosa".

No poema, como afirma Del Priori (2005), "o caráter doméstico das personagens, sua submissão e identificação com a mulher 'do lar' é total. Mas elas correspondem a um padrão não mais existente; um padrão que deixava saudades, deixava um vazio; elas não mais estão" (DEL PRIORI, 2005, p. 270). Nos versos das duas canções, tanto Amélia quanto Emília, as graciosas, pertencem ao passado. As coincidências de desejos e motivos de saudade daquelas que não mais estão são parecidas nas duas canções: Emília é mulher; Amélia, mulher de verdade; os dois oradores evocam a figura divina para acentuar o sentido da perda: Ai, meu Deus, que saudade da Amélia - Papai do céu é que sabe a falta que ela me faz. As duas canções centram-se nos desejos, concepções e aspirações do orador: (eu) nunca vi - eu quero uma mulher. Ambos estão, no momento da elocutio, imersos no poder da memória e se sentem inseguros e frágeis. Os dois oradores clamam não por amor físico, mas por proteção e, ao que parece, por uma figura materna. Amélia até dizia: meu filho, o que se há de fazer? O tom afetivo pode significar "meu querido, meu amor", mas remete-nos à dimensão da mulher-mãe, quase santa em demonstrações de bondade extremada.

Os dois oradores têm saudade de uma mulher que não demonstrava desejos e aspirações; têm saudade de uma amada, que se oferece à felicidade plena, quase ingênua. Por outro lado, e paradoxalmente, essa criatura precisa ter doses fortes daquelas da raça de Prometeu: serem racionais e trágicas como o próprio deus da civilização, do trabalho, da cultura e, também, da repressão. Amélia é guerreira, passiva e conformada, retrato malfeito de algumas mulheres de Atenas, prisioneira inescapável de um papel social denominado "serva da espécie". Emília não parece ser diferente.

Amélia é importante, sim, mas se é aparentemente tão valorizada, torna-se vítima de uma catastrófica traição da enunciação no enunciado: $A i$, meu Deus, que saudade da Amélial Aquilo sim é que era mulher. A saudosa figura sequer merece o pronome "aquela", usado em português para designar pessoas. Para caracterizá-la o orador se vale do indefinido aquilo, comumente usado para objetos. Mais que isso: não há uma só vez no poema a palavra "amor". Não se sabe, pois, se o orador amou Amélia, mas entende-se claramente que a relação que sustenta no momento da enunciação é idealizada, romântica e o impulsiona à negação da individualidade contida em alguém com quem vive no presente. 
A tensividade retórica ganha corpo pelo processo de sensibilização e articula, simultaneamente, intensidade do dizer e temporalidade ao contrapor passado $\times$ presente. No contexto tenso e desesperançado, o orador retira a armadura do macho e revela sua incapacidade de lidar com a situação vivida: Não vê que eu sou um pobre rapaz?. A relação criada exalta o "conforme-se, adapte-se" e deixa entrever a concepção do que seria uma mulher de verdade: um ser plenamente adaptável aos desejos do outro. O orador age como uma espécie de Procusto, aquele que aprisionava os viajantes e os "adaptava" a uma cama de ferro: se eram grandes demais para a medida, mutilava-os terrivelmente até ajustá-los ao tamanho da cama; se eram pequenos, encontrava formas para esticá-los até que atingissem a medida. Como Procusto, o orador tenta ajustar a nova mulher à cama antiga, ao já-vivido e sedimentado na cultura.

No jogo argumentativo que convida ao conformar-se, ao adaptar-se, o orador trabalha com valores característicos das sociedades patriarcais: deseja a perda da identidade "individual" da amada atual para que assuma uma identidade social consolidada como verdade para os padrões masculinos. Por não se enquadrar nessa idealização, a mulher muito exigente gera revolta. É impossível medir, pela superfície textual do poema, a extensão semântica do termo "exigência", mas o que se ressalta é que a interlocutora demonstra coragem de reivindicar, de mostrar desejos, de interferir no jogo estabelecido para a convivência entre um homem e uma mulher. A amada, por fazer tanta exigência, num grau nunca visto pelo orador, fere um princípio básico: deixa de identificar-se com o feminino sedimentado e reconhecido.

À sua maneira, o orador pretende sustentar sua argumentação pautada em estereótipos existentes desde a Grécia Antiga, que persistiram na Idade Média e atravessaram a Idade Moderna. A concepção do feminino «verdadeiro» é, evidentemente, a de sexo frágil, da figura angelical da mulher tão decantada no Romantismo mundial. Contaminado pela visão romântica do ente amado, o esforço retórico do orador, que embora enfatize seu lado pobre, é característico do comportamento burguês, que sempre se esforça pela delimitação de funções e papéis sociais. Em resumo, a argumentação confronta, antiteticamente, os hábitos e costumes de uma mulher antiga, idealizada, sublimada, com os "vícios" de uma mulher classificada como fútil, interesseira, consumista e insensível: Você só pensa em luxo e riqueza/ Tudo o que você vê, você quer. E essa figura antitética que perpassa o poema tem um valor metonímico que coloca em jogo todas as "conservadoras" em oposição a todas as "liberais".

A ideia de submissão e controle se infiltra passionalmente na canção. O conflito está criado e, sensivelmente, o orador tira partido dos valores do auditório para hierarquizar o preferível: a mulher precisa ter consciência, enxergar as limitações financeiras e emocionais do companheiro, pensar menos 
em dinheiro para que deixe saudade. Evidentemente, toda essa acusação é parte de uma estratégia argumentativa pelo uso de uma falácia denominada "da enumeração", em que se faz uma generalização apressada, pautada em casos ou dados insuficientes ou não claramente demonstráveis: tudo o que você vê, você quer. Você só pensa em luxo e riqueza. Essa falácia encampa o argumento contra o homem: o orador ataca a mulher inominada como se fosse um adversário, com intenção sensível de desequilibrá-la. Não há espaço para contra-argumentos no poema e, assim, o silêncio do interlocutor dá a entender que o ataque à pessoa não leva em conta a eventual defesa já dita ou que ainda será enunciada nesse contexto de discussão da relação amorosa. A pergunta final da primeira estrofe é também uma figura de presença, pois põe em relevo uma resposta já conhecida que apenas reforça o aspecto passional do orador.

Ao resumir seu ethos em pobre rapaz, o orador conduz o auditório para um estado de espírito até explícito: angariar solidariedade. O objetivo é enternecer, impactar o auditório e estabelecer um acordo: o orador sofre e o auditório dele deve se condoer. Esse movimento retórico é muito persuasivo: o orador que fala para um auditório particular enuncia também para outro, universal, que escuta o que se diz entre quatro paredes e, nesse sentido, pretende provocar pathos: conclamar o auditório a enternecer-se com o acúmulo das exigências, enraivecer-se com a crueldade da mulher, indignar-se com a situação conflitante e, para ressaltar o que seria digno de apreço, faz assomar o detestável, o desprezível, a crueldade humana, a potencialidade insondável do amar e da virtude desse ato no plano do desejável. Evidencia-se o universo de crenças do orador: a mulher não pode ocupar, na cultura, uma suposta posição ativa, capaz de alojar-se em lugares, posições e deveres identificados como caracteristicamente masculinos.

Retoricamente, a estratégia é bem conhecida. O orador clama por um processo de racionalização: o ethos da amada-lembrada está em consonância com as aspirações do apaixonado. $\mathrm{O}$ ethos da nova amante, porém, precisa reconstruir-se a partir do modelo racionalizado pelo próprio orador. $\mathrm{Na}$ verdade, qualquer manifestação de racionalidade está sempre norteada por alguma espécie de desejo, pois é o desejo que põe as paixões em movimento. É nesse sentido que devemos associar a noção de ethos a pathos, na medida em que consideramos nossos desejos e preferências como aquilo que nos dispõe a agir de um modo e não de outro. O modo autoritário de agir com as paixões congrega emoção e racionalidade para subjugar o outro aos desejos do orador.

Não se sabe, na canção, o destino de Amélia. Sabemos, sim, que não era vaidosa, que amparava o amado nos momentos de contrariedade. Sua lembrança de submissão e gentileza extremada é a tônica que alicerça os desejos do orador e constrói a idealização de uma "mulher de verdade": 
o ser amado é aquele que se regozija com nossos bens e sofre com nossas tristezas e limitações, sem outra razão que o nosso interesse. Assim, tanto as aflições quanto os prazeres não são produtos do sujeito que assim sente, mas, sim, resultado do desejo e da sinalização do outro.

Enfim, para conquistar pathos, o orador constrói o ethos da amada a partir das opiniões pessoais, características da doxa. No caso em análise, a aproximação é desigual: por sofrer uma condição, o orador quer valer-se do discurso autorizado do macho para mudar a condição do outro, sem, porém, racionalizar sua própria condição no processo. Só consegue entender "emoção" ou "paixão" no sentido de "padecer" e a seu modo constrói o logos, termo grego utilizado para referir-se ao pensamento lúcido, à conduta esclarecida, à razão. Nessa perspectiva, a mulher é "paciente”, precisa assumir uma postura passiva”, receber a sua "forma" de outrem e por isso mesmo deve ser determinada por exigências extrínsecas.

\section{Considerações Finais}

Como se percebe, Ataulfo e Lago apropriaram-se da dinamicidade da linguagem em funcionamento para colocar em relação sujeitos e sentidos, afetados por sua língua, sua história e efetivaram seu dizer num complexo processo de constituição de discursos e de produção de sentidos que, traduzidos em canção popular, infiltraram-se pelos espaços midiáticos, formaram opiniões, moldaram costumes, edificaram modos de vida e traduziram um pouco da história de nossa gente e da potência persuasiva do discurso poético. Com sua composição, os oradores contribuíram para a demonstração nítida de velhas identidades sociais que a contemporaneidade, por uma série de razões, conseguiu gradativamente transformar. Ao mostrar dois comportamentos bem distintos numa mesma canção, os compositores também demonstram que, já na década de quarenta, um discurso instituinte esforçava-se para abalar o discurso dominante. Saudade da Amélia, então, produto de resquícios discursivos de outras épocas, permanece de um modo ou outro, como documento histórico, no cantar do povo brasileiro. O refrão, altamente melódico e de fácil memorização, traduz um ethos feminino construído sob a perspectiva do masculino.

A singeleza dessa criação esconde/mostra o movimento das paixões quando observada num contexto retórico: como canção popular, alegrou o auditório brasileiro que, em algum momento no tempo, deixou-se embalar pelo discurso do outro e experimentou - em menor ou maior intensidade - as paixões evocadas. Saudade da Amélia, nesse sentido, quer como entretenimento quer como documento histórico, mantém relação direta com a produção de discursos sociais 
construídos na primeira década do século XX. Com efeito, cremos, é impossível tratar-se da mulher, sem que se desvende também o homem, sem que o masculino seja explicitado, sem que os afetos sejam suscitados e, por consequência, as paixões desvelem, na lírica amorosa, o fundamental do feminino na perspectiva de uma época. Enfim, as temáticas da mulher e do amor, que entraram juntas na poesia ocidental, podem ser reciprocamente aferidas.

Muitas mulheres ainda vivem sob a sombra de costumes praticados na Grécia antiga há quase 400 anos antes de Cristo. Há na cultura brasileira, um ranço patriarcal ainda bastante acentuado, que, embora não explícito, aproxima algumas mulheres de nosso tempo a Penélope e Helena, famosíssimas personagens de Homero. A primeira, mulher de Ulisses, herói da Odisseia, durante os vinte anos em que o marido ficou longe de casa, portou-se com dignidade e absoluta fidelidade. A segunda, motivo da guerra de Tróia, é símbolo da beleza, mulher para quem os maridos sempre voltam correndo, depois de se deitarem com as elegantes e distintas cortesãs, as falenas.

O texto, pois, escancara a tradição e nos possibilita interpretar o sentido de arete, cantado com todas as letras em Amélia: considera-se virtuoso não aquele que se esforça para se dominar, mas aquele que de fato domina e utiliza adequadamente as suas paixões. A virtude só é possível quando conhecemos, hierarquizamos e regulamos as paixões, quando nos colocamos em um ponto intermediário entre o grau mais alto de passionalidade e o grau mais baixo de apatia para, assim, aprimorarmos nossas condutas. $\mathrm{Na}$ canção analisada, esse modo de ver implica a ideia de refreamento ou de tentativa de anulação de afetividade para fazer sobressair o cuidado que o orador julga necessitar. Em síntese, pretende domínio consentido, moralmente válido no contexto em que se encontra.

Ainda que em Aristóteles não tenhamos essa moralidade concebida como completa submissão ao logos, como no estoicismo, ou um tribunal da razão que nos conduz na busca de uma norma moral universalmente válida para todos e em todas as circunstâncias, como em Kant, foi a partir da tradição aristotélica que surgiu essa "interpretação legislativa" do logos, associada à repressão das paixões em nome de uma lei moral universal. Segundo essa lei, pode-se e deve-se reprimir aquilo que todos os homens "democraticamente iguais" são capazes de compreender, pelas mesmas razões, como suspeito e perigoso.

O orador, na canção, deseja, como pretendia a tradição ocidental, uma razão "não-perturbada" pelos desejos, uma razão sábia e neutra, em oposição à afetividade ou a uma razão "passional" que não é própria da paixão propriamente dita. Em resumo, mesmo a razão que se aponta crítica é, como todas as outras, sob este aspecto, uma espécie de desrazão, na medida em que seu conteúdo é determinado por um desejo, a saber, o desejo de razão. 
A ânsia de dominação é mesmo pathos, também construído e cultivado em nossa história cultural por mecanismos de dominação e controle. Para o orador, a feminilidade (ainda) é um conjunto de atributos que a mulher precisa oferecer ao homem para financiar, nele, a virilidade. Assim, a masculinidade precisaria ser sustentada pelo trabalho ativo de produção da passividade feminina.

\section{REFERÊNCIAS}

ALBALADEJO, Tomás M. Retórica. Madrid: Sintesis, 1991.

ANDERY, Maria Amália et al. Para compreender a ciência: uma perspectiva histórica. 8. ed. Rio de Janeiro: Espaço e Tempo; São Paulo: Educ, 1999. 436 p.

CALAME, Claude. Eros na Grécia antiga. São Paulo: Perspectiva, 2013.

DEL PRIORI, Mary. História do amor no Brasil. São Paulo: Contexto, 2005.

FERREIRA, Luiz Antonio. Maria vai mesmo com as outras? Ethos e paixões na canção popular. In: CARMELINO, Ana Cristina; PERNAMBUCO, Juscelino; FERREIRA, Luiz Antonio (orgs.). Os caminhos do texto: atos de leitura. Franca, SP: UNIFRAN, 2007, p. 99-128.

FERREIRA, Luiz Antonio. Leitura e persuasão - princípios de análise retórica. São Paulo: Contexto, 2010.

FONSECA, Ana João Mexia Sepulveda da. A identidade masculina segundo Robert Bly: O paradoxo entre o real e o imaginado. Dissertação de Mestrado em Estudo Americanos. Lisboa: Universidade Aberta, 1998. 137 f.

SCHOEPFLIN, Maurizio (ed.). O amor segundo os filósofos. Tradução Antonio Angonese. Bauru, SP: EDUSC, 2004.

SIGNORINI, Inês (org.) Lingua(gem) e identidade. Campinas: Mercado Aberto; São Paulo: Fapesp, 1998. 